\title{
In situ synchrotron study on the interplay between martensite formation, texture evolution and load partitioning in low-alloyed TRIP steels
}

\author{
E. Jimenez-Melero ${ }^{\mathrm{a}, *}$, N.H. van Dijk ${ }^{\mathrm{a}}$, L. Zhao ${ }^{\mathrm{b}, \mathrm{c}}$, J. Sietsma ${ }^{\mathrm{c}}$, J.P. Wright ${ }^{\mathrm{d}}$, S. van der Zwaage \\ a Fundamental Aspects of Materials and Energy, Faculty of Applied Sciences, Delft University of Technology, Mekelweg 15, 2629 JB Delft, The Netherlands \\ ${ }^{\mathrm{b}}$ Materials Innovation Institute M2i, Mekelweg 2, 2628 CD Delft, The Netherlands \\ ${ }^{c}$ Department of Materials Science and Engineering, Delft University of Technology, Mekelweg 2, 2628 CD Delft, The Netherlands \\ d European Synchrotron Radiation Facility, 6 Rue Jules Horowitz, BP 220, 38043 Grenoble Cedex, France \\ e Faculty of Aerospace Engineering, Delft University of Technology, Kluijverweg 1, 2629 HS Delft, The Netherlands
}

\section{A R T I C L E I N F O}

\section{Article history:}

Received 24 January 2011

Received in revised form 18 March 2011

Accepted 27 April 2011

Available online 5 May 2011

Keywords:

Martensitic transformations

TRIP steel

Metastable austenite

Synchrotron X-ray diffraction

Mechanical characterization

\begin{abstract}
A B S T R A C T
We have studied the micromechanical behaviour of two low-alloyed multiphase TRIP steels with different aluminium contents by performing in situ high-energy X-ray diffraction experiments at a synchrotron source under increasing tensile stress levels. A detailed analysis of the two-dimensional diffraction data has allowed us to unravel the interplay between the martensite formation, the texture evolution and the load partitioning, and to correlate the observed behaviour to the macroscopic response of the material. The high aluminium content TRIP steel grade presents a higher volume fraction of retained austenite at room temperature that transforms more gradually into martensite under deformation, providing a larger uniform elongation. The comparison between the observed transformation behaviour and the texture evolution indicates that the $\langle 100\rangle$ component along the loading direction corresponds to a low critical stress for the transformation. The evolution of the elastic strains revealed the occurrence of a significant load partitioning before reaching the macroscopic yield strength, which becomes more pronounced in the plastic regime due to the progressive yielding of the different grains in the polycrystalline material. This opens the door to tailor the austenite stability by altering the distribution in grain size, local carbon content, and grain orientation in order to produce the optimal load partitioning and work hardening for improved combinations of strength and formability in low-alloyed TRIP steels.
\end{abstract}

(ㄷ) 2011 Elsevier B.V. All rights reserved.

\section{Introduction}

Current trends in modern vehicle concepts steer the ongoing material research for automotive applications towards new solutions for future lightweight vehicle designs. The criteria for a proper (multi-)material selection include a significant vehicle weight reduction, thus decreasing the energy consumption and environmental impact, without either increasing the production costs or compromising the passengers' safety and comfort [1-3]. This has triggered the development of a new generation of high-strength steels with improved formability, so that thinner metals sheets can be used to produce lighter auto bodies [4]. Low-alloyed TRansformation-Induced Plasticity (TRIP) steels are considered promising high-strength automotive materials, where the key to attain high formability levels seems to reside in the

\footnotetext{
* Corresponding author at: Fundamental Aspects of Materials and Energy, Department of Radiation, Radionuclides and Reactors, Faculty of Applied Sciences, Delft University of Technology, Mekelweg 15, 2629 JB Delft, The Netherlands. Tel.: +31 15 2781192; fax: +31 152788303 .

E-mail address: E.Jimenez-Melero@tudelft.nl (E. Jimenez-Melero).
}

presence of a relatively small fraction $(<20 \mathrm{vol} . \%)$ of metastable austenite retained at room temperature within the complex ferrite-bainite-(martensite) microstructure of low-alloyed TRIP steels [5-7]. The metastable austenite phase will respond to mechanical and/or thermal stimuli by transforming progressively into harder martensite [8].

In order to design and control the mechanical response of TRIP steels for selected automotive components, a thorough understanding of the processes occurring at the micro-scale induced by the applied stress is clearly required. In view of the strong correlation between the complex deformation/transformation behaviour of TRIP steels at a micro-scale and the macroscopic material response $[5,9,10]$, a great effort has been made in recent years to develop TRIP microstructures with the adequate combination of phases [11-13], and to collect information about their behaviour under deformation using a broad range of experimental techniques including conventional X-ray diffraction [8,14,15], Mössbauer spectroscopy [16], atomic force microscopy [17], transmissionelectron microscopy $[18,19]$ and electron back-scattered diffraction [20,21]. However, most of the available information has been derived from ex situ and/or (near-) surface studies, and do not accurately capture the complex deformation/transformation 
process that takes place in TRIP steels. As a consequence, relevant questions for the design and production of new TRIP steel grades with the desired mechanical properties do still not have a unified explanation, such as what the exact contribution of the TRIP effect is to the high work hardening rate and the large ultimate elongation observed in these materials, or what the local microstructural characteristics of the austenite grains and their surrounding evolving matrix are at the onset of the transformation and how they affect the stability of the austenite grains. In parallel to these experimental efforts, multi-scale models have been developed in the last decade to link the microstructural evolution of TRIP steels to their macroscopic response under different loading conditions [22-26]. However, these multi-scale models still cannot reliably predict key material properties, such as the delay of necking or the ultimate elongation, based on an accurate description of the deformation/transformation behaviour at the micro-scale.

The availability of intense neutron and high-energy synchrotron X-ray beams at several large scale facilities worldwide has opened the door to probe the bulk mechanical behaviour of polycrystalline materials during in situ diffraction studies under deformation $[27,28]$. In recent years, the use of neutron and/or high-energy X-ray diffraction has led to new insights into the deformation behaviour of a wide range of technologically relevant materials, ranging from stainless steel [29], copper [30] and magnesium alloys [31] to shape memory alloys [32] and nickel-base superalloys [33]. In situ neutron and high-energy $\mathrm{X}$-ray diffraction experiments have in the last years also been reported on low-alloyed TRIP steels [34-38]. However, due to the composite-like TRIP microstructure and the complex deformation/transformation behaviour in these materials, the reported neutron and synchrotron experiments were designed to focus on selected microstructural aspects of the material during deformation, especially on the stress partitioning between the constituent phases.

The aim of the present paper is to assess in situ the changes induced by the applied tensile stress on the main microstructural parameters governing the mechanical behaviour of both the metastable austenite phase and the surrounding ferritic matrix in low-alloyed TRIP steels: phase fractions, texture effects and occurrence of strains. The characteristics of each phase and the interaction between phases will be correlated to the macroscopic response of the material at each deformation step up to rupture. In order to achieve this goal, we have studied two TRIP samples differing in their aluminium content by performing in situ high-energy X-ray diffraction at a synchrotron source during deformation. The purpose of using two aluminium-containing samples is twofold: (1) to obtain two different starting microstructures and (2) to link the observed micro- and macro-scale behaviour to an industrial process parameter, i.e. the overall aluminium content. In recent years, we have succeeded in monitoring the temperature-dependent martensitic transformation of metastable austenite in TRIP steels on both an average [39] and singlegrain level [40-42]. In the present work, we characterize in detail the effect of deformation on these complex multiphase TRIP steels.

\section{Experimental}

\subsection{Sample preparation}

The chemical composition of the two studied TRIP steel grades is shown in Table 1. Cylindrical dog-bone-shaped tensile specimens with a gauge length of $10 \mathrm{~mm}$ and a diameter of $1 \mathrm{~mm}$ were machined from 6-mm thick hot-rolled sheet materials. The cylindrical axis of the samples was selected to be parallel to the rolling
Table 1

Chemical composition of the two TRIP steels used in this study (wt.\%), with balance Fe.

\begin{tabular}{llllll}
\hline Material & $\mathrm{C}$ & $\mathrm{Mn}$ & $\mathrm{Si}$ & $\mathrm{Al}$ & $\mathrm{P}$ \\
\hline $\mathrm{Al}_{0.4}$ & 0.188 & 1.502 & 0.254 & 0.443 & 0.015 \\
$\mathrm{Al}_{1.8}$ & 0.218 & 1.539 & 0.267 & 1.750 & 0.018 \\
\hline
\end{tabular}

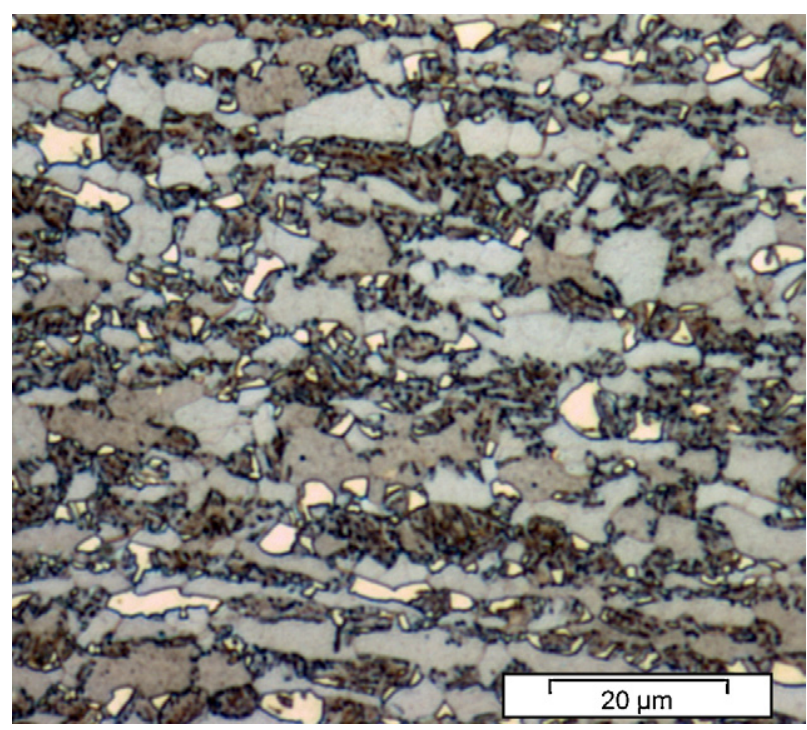

Fig. 1. Optical micrograph of the $\mathrm{Al}_{1.8}$ TRIP material. The room-temperature multiphase microstructure contains a metastable austenite phase (white) within a matrix of ferrite (grey) and bainite (dark grey) phases.

direction (RD) of the sheet material. A mark parallel to the normal direction of the sheet material was made on the top part of the samples, in order to keep track of the normal (ND) and transverse (TD) directions of the starting sheet material when studying texture effects during the in situ X-ray diffraction experiments under deformation. In order to generate the starting (non-deformed) TRIP microstructures at room temperature with a significant amount of retained austenite, the samples were initially annealed in a salt bath at the intercritical temperature $T_{i}$ to obtain a ferrite-austenite microstructure. The intercritical holding time $t_{i}$ was selected to be $30 \mathrm{~min}$ for both materials. The samples were subsequently quenched to a lower temperature in order to trigger the bainitic transformation of part of the intercritical austenite. After a holding time $\left(t_{b h}\right)$ of $60 \mathrm{~s}$ at the bainitic temperature of $T_{b h}=673 \mathrm{~K}$, the samples were quenched in water to room temperature. The relevant parameters for the heat treatment of the two specimens are collected in Table 2 . The intercritical temperature $T_{i}$ for each chemical composition was chosen to obtain the maximum fraction of metastable austenite in the room-temperature microstructure. Fig. 1 shows an optical micrograph of the $\mathrm{Al}_{1.8}$ TRIP material at room temperature. The average austenite grain size is about $3 \mu \mathrm{m}$ in both samples. For a detailed characterization of the initial microstruc-

\section{Table 2}

Relevant parameters describing the heat treatment of the two TRIP samples: the thermodynamic transformation temperatures $\left(A_{1}^{-}, A_{1}^{+}\right.$and $\left.A_{3}\right)$ calculated using the thermodynamic database MTDATA, together with the intercritical annealing temperature $\left(T_{i}\right)$, time $\left(t_{i}\right)$ and austenite fraction $\left(f_{\gamma}^{i}\right)$. The samples were quenched to a bainitic holding temperature $T_{b h}$ and held for a period $t_{b h}$, before finally quenching to room temperature.

\begin{tabular}{lccllllll}
\hline Material & $A_{1}^{-}(\mathrm{K})$ & $A_{1}^{+}(\mathrm{K})$ & $A_{3}(\mathrm{~K})$ & $T_{i}(\mathrm{~K})$ & $t_{i}(\mathrm{~min})$ & $f_{\gamma}^{i}(\%)$ & $T_{b h}(\mathrm{~K})$ & $t_{b h}(\mathrm{~s})$ \\
\hline $\mathrm{Al}_{0.4}$ & 967 & 983 & 1127 & 1073 & 30 & 37 & 673 & 60 \\
$\mathrm{Al}_{1.8}$ & 1016 & 1035 & - & 1173 & 30 & 52 & 673 & 60 \\
\hline
\end{tabular}

Note: $\mathrm{Al}_{1.8}$ steel cannot be made in the pure austenite phase. 


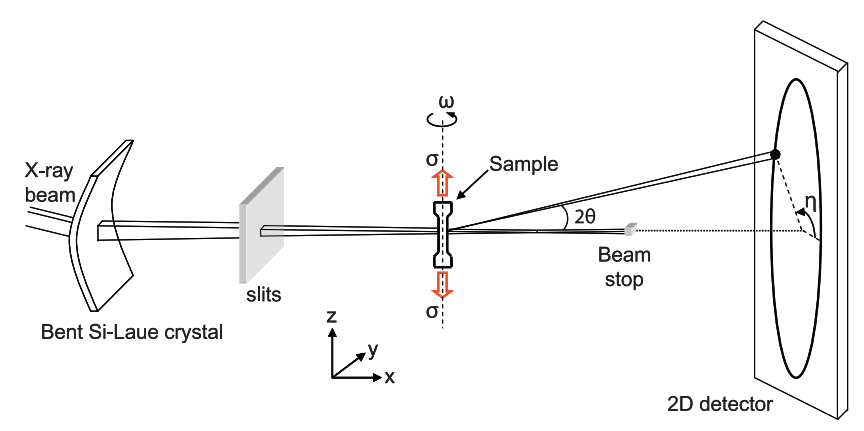

Fig. 2. Schematic representation of the HEXRD setup used for the in situ synchrotron diffraction experiments on low-alloyed TRIP steels under uniaxial tensile stress. A monochromatic high-energy X-ray beam illuminates the cylindrical sample mounted on the tensile rig. The beam size is defined by the slits situated between the silicon monochromator and the sample. The Si-Laue crystal scatters vertically and is bent towards the vertical around a horizontal axis. The tensile rig is placed on a table that can be translated in three dimensions and rotated along the cylindrical axis of the sample ( $\omega$-rotation). The load $(\sigma)$ is applied perpendicular to the incoming X-ray beam. The diffracted intensity is collected on the two-dimensional Frelon CCD detector placed behind the sample. The scattering angle $(2 \theta)$ and the azimuth angle $(\eta)$ are indicated in the figure.

ture of both studied TRIP steel grades we refer to our previous publications [40-42].

\subsection{High-energy synchrotron X-ray experiment}

The two TRIP microstructures and their response to the applied tensile stress were studied by means of in situ high-energy X-ray diffraction (HEXRD). The experiment was performed at the ID11 beam line of the European Synchrotron Radiation Facility (Grenoble, France). For a detailed description of the beam line see [43]. The samples were mounted in a $2-\mathrm{kN}$ micro-tensile rig placed on a $X Y Z$ translation table that allowed translations in three dimensions in space, together with $\omega$-rotations around the sample cylindrical axis. The samples were aligned with their texture mark parallel to the frame of the rig, while the loading direction (LD) coincided with the rolling direction (RD) of the sample. Fig. 2 displays a schematic representation of the HEXRD setup. An intense monochromatic Xray beam with an energy of about $69 \mathrm{keV}(\lambda=0.17986 \AA)$ and a beam size of $100 \times 100 \mu \mathrm{m}^{2}$ illuminated the sample. The diffracted intensity was recorded on a two-dimensional Frelon CCD detector placed behind the sample [44]. The sample was continuously rotated around its cylindrical axis in steps of $\Delta \omega=3^{\circ}$, covering a total $\omega$-range from 45 to $135^{\circ}$. During each of these steps in $\omega$, the sample was rotated at constant angular velocity while the Xray shutter was open and the detector was exposed. The exposure time for each diffraction pattern was $t_{\text {exp }}=1 \mathrm{~s}$.

Once the starting microstructures were characterized, their mechanical response was assessed in situ both at a macro- and micro-scale by step-wise applying increasing tensile stresses in strain-control mode up to the material rupture. The loading direction was perpendicular to the incoming X-ray beam. After each deformation step, the diffraction patterns were recorded for the above-mentioned scan in $\omega$. In this way, the mechanical behaviour of the constituent phases in the microstructure could be correlated to the measured macroscopic stress-strain curve of the material. The occurrence of the necking phenomenon occurred outside the sample volume illuminated by the X-ray beam. In order to accurately determine possible variations in the sample-to-detector distance during the deformation process, $\mathrm{LaB}_{6}$ calibration powder (NIST Standard Reference Material SRM-660) was deposited directly onto the sample surface at a distance of $2.6 \mathrm{~mm}$ above the studied volume. For each step in elongation, the sample was moved downwards in order to illuminate the $\mathrm{LaB}_{6}$ powder and collect its diffraction pattern.

\subsection{Analysis of the diffraction data}

The measured data consisted of a series of two-dimensional diffraction patterns as a function of the elongation and the $\omega$ angle for the two TRIP steels and the $\mathrm{LaB}_{6}$ calibrant. The diffraction patterns of $\mathrm{LaB}_{6}$ at different elongation steps were employed to determine the relevant instrumental parameters (sample-detector distance, coordinates of the beam centre and the inclination of the detector with respect to the direct beam) using the FIT2D software package [45]. For each sample and elongation step, all the twodimensional diffraction patterns corresponding to the complete $\omega$-range covered in this experiment were summed. Afterwards, the resulting two-dimensional patterns were integrated along the scattering angle $(2 \theta)$ over all azimuth angles, so that one-dimensional diffraction patterns (intensity versus $2 \theta$ ) were obtained.

The average behaviour during deformation of the phases present in the microstructure was inferred from the Rietveld analysis of the one-dimensional diffraction patterns using the Fullprof software package [46]. The evolution of the integrated intensity of the different $\{h k l\}$ reflections coming from each of the phases during deformation provides information about changes in phase fractions and/or texture, while the shifts in peak positions reveal changes in the average lattice parameter with respect to the starting condition. These peak shifts can be translated into the corresponding average elastic phase strains $\left(\left\langle\varepsilon_{p h}\right\rangle\right)$ according to:

$\left\langle\varepsilon_{p h}\right\rangle=\frac{a_{p h}-a_{p h}^{0}}{a_{p h}^{0}}$

where $a_{p h}$ and $a_{p h}^{0}$ correspond to the lattice parameter at a given deformation step and at zero deformation, respectively. The current analysis determines the strain development during deformation using the zero-deformation state as reference. The evolution of $\left\langle\varepsilon_{p h}\right\rangle$ with the applied stress provides information about the load partitioning between the different phases in the microstructure. Furthermore, we have carried out a single-peak fit of selected (weakly overlapping or non-overlapping) reflections to a pseudoVoigt profile function, in order to probe the load partitioning between subsets of grains within each phase who are in Bragg condition for specific $\{h k l\}$ lattice planes and grain orientations with respect to the incoming X-ray beam. The observed shift in the position of individual peaks manifests in an increase in the average elastic lattice plane strain $\left(\left\langle\varepsilon_{h k l}\right\rangle\right)$ which can be calculated using the expression:

$\left\langle\varepsilon_{h k l}\right\rangle=\frac{d_{h k l}-d_{h k l}^{0}}{d_{h k l}^{0}}$

where $d_{h k l}$ and $d_{h k l}^{0}$ correspond to the lattice plane spacing at a given deformation step and at zero deformation, respectively. In this way, we were able to monitor the inter- and intra-phase stress partitioning together with the stress-induced martensitic transformation of the metastable austenite grains for increasing tensile stresses.

Texture effects manifest themselves as systematic variations in intensity along the diffraction rings in the two-dimensional pattern. In order to perform a texture analysis via the Rietveld method and monitor possible texture changes during deformation, the two-dimensional patterns were integrated along the scattering angle over regions in the detector covering $5^{\circ}$ along the azimuth angle from $0^{\circ}$ to $360^{\circ}$ for selected steps in elongation. Each two-dimensional pattern then yielded 72 one-dimensional diffraction patterns. The recorded intensity along the azimuth angle is 


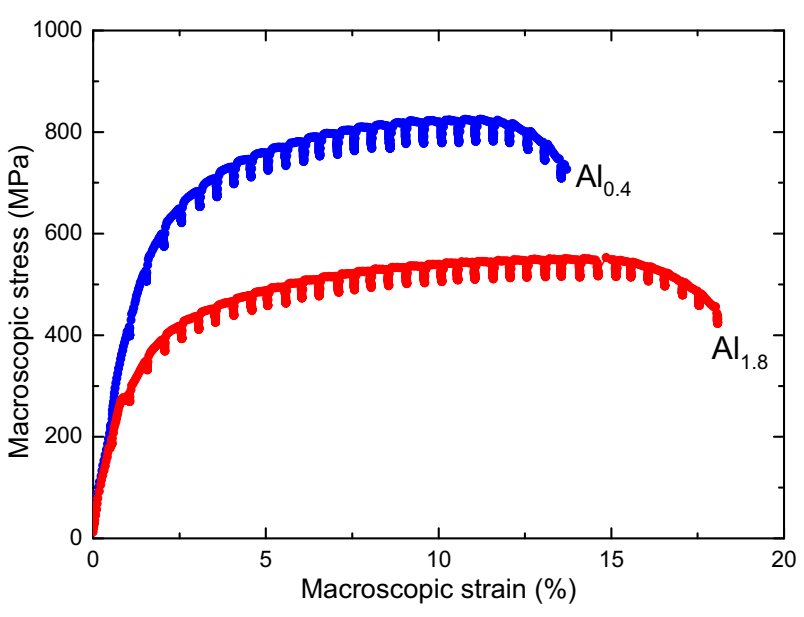

Fig. 3. Macroscopic (engineering) stress-strain curves of the two studied TRIP steels.

proportional to the pole density on the orientation sphere. However, a diffraction ring recorded at a certain sample rotation $\omega$ only covers a limited region in the $\{h k l\}$ pole figure corresponding to a small circle with a radius of $90^{\circ}-\theta$. If we view the pole sphere along the $\omega$-rotation axis, the small circles on the pole figure appear as a pair of lines separated by a distance $2 \theta$. Rotating the sample around its cylindrical axis rotates the lines on the pole figure by the same angle. By combining the 30 twodimensional patterns in the covered $\omega$-range from 45 to $135^{\circ}$ $\left(\Delta \omega=3^{\circ}\right)$, half of the pole figure is covered. The resultant $72 \times 30$ one-dimensional patterns were analysed simultaneously via the Rietveld method using the MAUD software package [47]. The E-WIMV algorithm capable of processing incomplete pole coverage was used for the texture refinement. This algorithm recalculates the pole figures from the estimated orientation distribution function using the available experimental pole figure data in an iterative process. More information about the E-WIMV algorithm and its implementation in MAUD can be found in Ref. [48,49]. When the material is being uniaxially deformed, the diffraction rings take an ellipsoidal form due to the occurrence of elastic strain in each of the phases present in the microstructure. As a consequence, the position of the intensity maximum varies with the azimuth angle. The stress analysis based on the $\eta$-dependence of the diffraction peak position was performed using the moment pole stress [50] with the Reuss model [51] and making use of the refined orientation distribution function (ODF) and the single-crystal elastic tensor reported in the literature for the austenite and ferrite phases [24,51]. According to the geometry of the experiment, the phase stresses fulfil the relationships: $\sigma_{i j}=0$ for $i \neq j, \sigma_{11}=\sigma_{22}, \sigma_{33}=-2 \sigma_{11}$, where $\sigma_{33}$ is the largest principal stress and takes a positive value for tension.

\section{Results and discussion}

\subsection{Macroscopic response of the material}

Fig. 3 shows the engineering stress-strain curves measured step-wise in strain-control mode during the in situ X-ray diffraction experiment for the two TRIP samples. Once a given strain level has been reached and kept constant, a small drop in load is observed. The diffraction patterns as a function of the $\omega$-angle were recorded once the stress relaxation effect was negligible. The degree of martensitic transformation of the metastable austenite at each deformation step is governed by the largest value of stress reached. Stress relaxation effects will not affect the monitored austenite mechanical stability. In TRIP steels the interrupted tensile curve is in close agreement with continuous tests [37]. Table 3
Table 3

Macroscopic parameters characterizing the mechanical response of the two studied TRIP steels to the applied tensile stress. These values are derived from the engineering stress-strain curve measured during the in situ X-ray diffraction experiment.

\begin{tabular}{lllll}
\hline Material & $\begin{array}{l}0.2 \% \text { proof } \\
\text { stress } \\
(\mathrm{MPa})\end{array}$ & $\begin{array}{l}\text { Tensile } \\
\text { strength } \\
(\mathrm{MPa})\end{array}$ & $\begin{array}{l}\text { Uniform } \\
\text { elongation } \\
(\%)\end{array}$ & $\begin{array}{l}\text { Total } \\
\text { elongation } \\
(\%)\end{array}$ \\
\hline $\mathrm{Al}_{0.4}$ & 525 & 825 & 10.8 & 13.6 \\
$\mathrm{Al}_{1.8}$ & 270 & 551 & 14.1 & 18.1 \\
\hline
\end{tabular}

contains the parameters that characterize the stress-strain curves of the two materials. It is noteworthy that the increase in the aluminium content leads to larger degrees of elongation. However, the opposite effect is observed for the material's strength: not only the tensile strength but also the $0.2 \%$ proof strength decrease significantly when the aluminium content increases from 0.4 to $1.8 \mathrm{wt} . \%$. The product of the uniform elongation and the tensile strength is a useful parameter to characterize the structural properties of a material. This product is found to vary significantly with the aluminium content from $8910 \% \mathrm{MPa}\left(\mathrm{Al}_{0.4}\right)$ to $7824 \% \mathrm{MPa}\left(\mathrm{Al}_{1.8}\right)$, respectively. The strong sensitivity for aluminium addition and microstructural parameters highlights the need to understand the complex microstructural evolution in TRIP steels in order to control and predict their macroscopic mechanical response.

\subsection{Average phase response}

\subsubsection{Martensitic transformation}

Fig. 4 shows as an example the two-dimensional diffraction patterns of the $\mathrm{Al}_{0.4}$ sample measured at an angle of $\omega=90^{\circ}$ for $0 \%$ and $10 \%$ engineering strain, together with the one-dimensional patterns at the same strain levels analysed using the Rietveld method. The diffraction patterns at $0 \%$ strain for both TRIP samples are composed of relatively intense rings that can be indexed with the body-centred cubic (bcc) structure of ferrite $(\alpha)$, together with weaker rings that correspond to the face-centred cubic (fcc) structure of retained austenite $(\gamma)$. The presence of bainitic ferrite does not lead to additional separate Bragg reflections. This indicates that there are no significant differences between the lattice parameter of the intercritical ferrite and the one of the bainitic ferrite [41]. The Rietveld analysis yielded an austenite fraction of $5.12(16) \%\left(\mathrm{Al}_{0.4}\right)$ and $7.57(20) \%\left(\mathrm{Al}_{1.8}\right)$, with a lattice parameter of $3.6073(1) \AA\left(\mathrm{Al}_{0.4}\right)$ and 3.6174(1) $\AA\left(\mathrm{Al}_{1.8}\right)$, respectively. The austenite lattice parameter depends on the chemical composition according to [39,52]:

$a_{\gamma}=3.556+0.0453 x_{C}+0.00095 x_{M n}+0.0056 x_{A l}$

where $a_{\gamma}$ is in $\AA$ and $x_{C}, x_{M n}$ and $x_{A l}$ are in wt.\%. Substituting the obtained values of the lattice parameter in Eq. (3) leads to a carbon content in austenite of $1.05 \mathrm{wt} . \%\left(\mathrm{Al}_{0.4}\right)$ and $1.11 \mathrm{wt} . \%\left(\mathrm{Al}_{1.8}\right)$, respectively. During the deformation process, there is a clear intensity reduction in the austenite reflections. This reveals that part of the metastable austenite transforms into martensite under applied stress. It is interesting to note that no additional reflections due to the newly formed martensite phase are observed in the diffraction patterns. The presence of martensite manifests itself as an increase in intensity of the bcc Bragg peaks. The formation of martensite with a cubic rather than tetragonal structure is in agreement with previous cooling experiments on the same TRIP steels [41]. Therefore, the analysis and interpretation of the diffraction data considers the bcc peaks as coming from the ferritic $(\alpha)$ matrix composed of intercritical ferrite, bainite and martensite.

Fig. 5 displays the experimental and calculated diffraction patterns as a function of the azimuth angle $(\eta)$ at $\omega=90^{\circ}$ for the $\mathrm{Al}_{0.4}$ sample at $0 \%$ and $10 \%$ engineering strain. Systematic variations in intensity as a function of $\eta$ are clearly seen at $0 \%$ strain in both the ferritic and the austenitic reflections. This intensity variation 

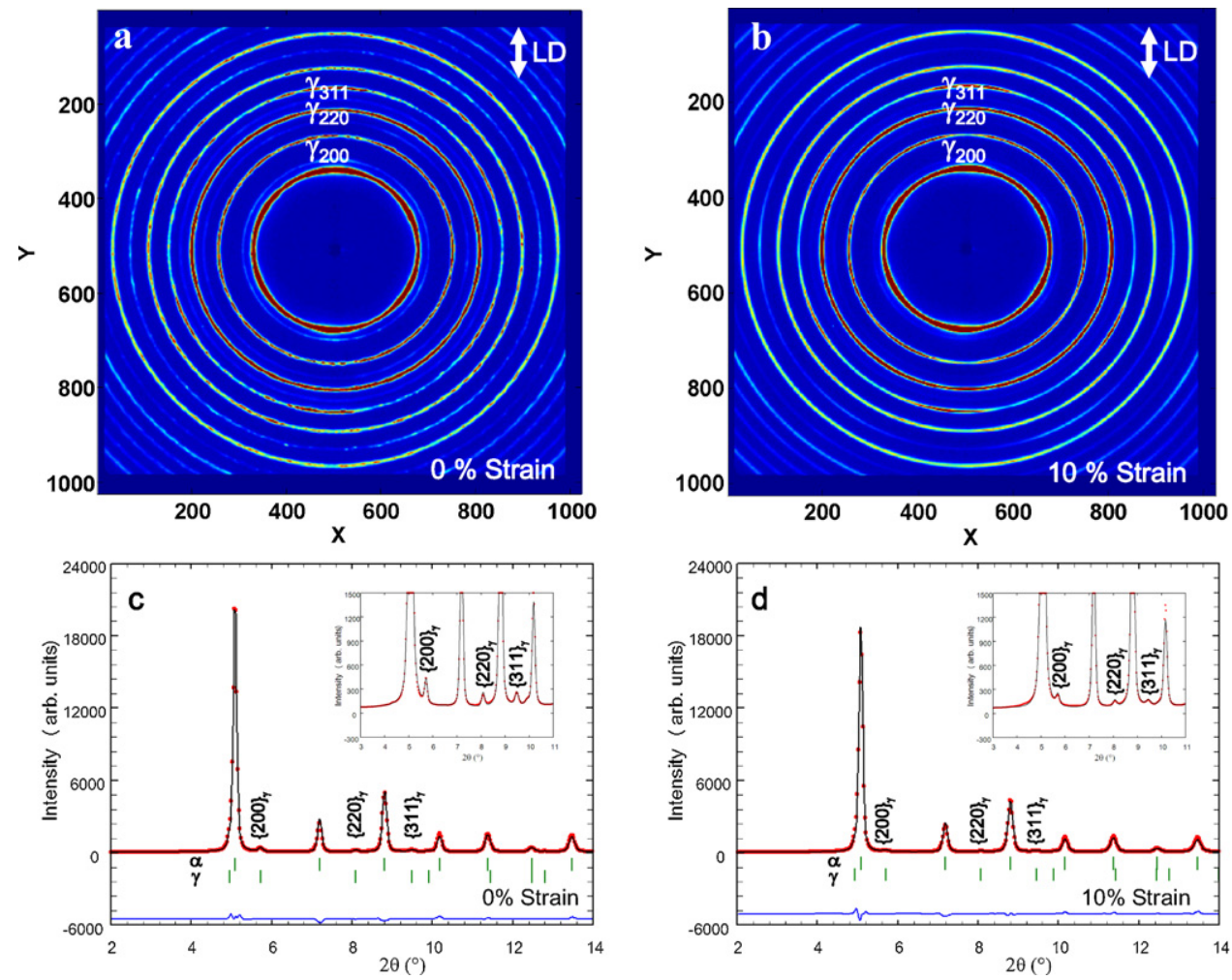

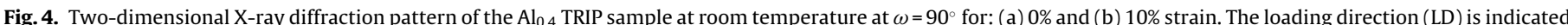

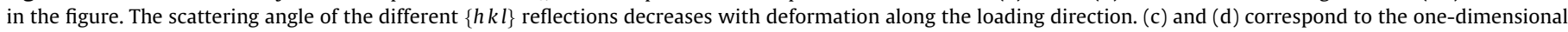

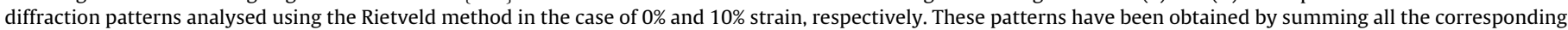

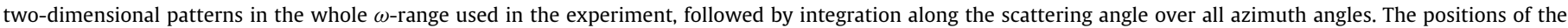

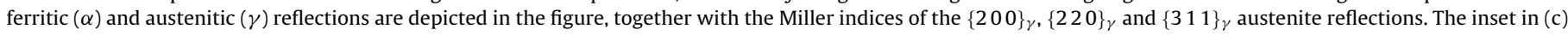
and (d) shows the relatively weak austenite reflections in detail.

reveals the presence of a non-random orientation distribution of the diffracting grains in both phases. This starting non-random state can be attributed to rolling and/or transformation texture produced during the sample preparation prior to the in situ X-ray diffraction experiment. Furthermore, the diffraction patterns reveal the occurrence of texture changes during deformation, together with the presence of elastic strains that lead to systematic peak shifts as a function of $\eta$. A combined Rietveld analysis of the data has allowed us to obtain information simultaneously on phase fractions, texture changes and elastic strains in both the transforming austenite phase and the ferritic matrix as a function of deformation.

The evolution of the austenite fraction and lattice parameter for the two TRIP steels is displayed in Fig. 6. The austenite fraction shows a significant reduction during the first steps of deformation, reaching a small plateau after $2 \%$ of deformation for both steels. This decrease in fraction amounts to about $1 \%$ of the retained austenite for the $\mathrm{Al}_{0.4}$ (from $5.12(16) \%$ at $0 \%$ to $4.03(15) \%$ at $2 \%$ deformation), while it corresponds to about $2 \%$ for the $\mathrm{Al}_{1.8}$ sample (from $7.57(20) \%$ at $0 \%$ to $5.63(16) \%$ at $2 \%$ deformation). Beyond $4 \%$ of deformation, a more gradual reduction in austenite fraction is observed until the maximum in the engineering stress-strain curve is reached. At this point, a significant fraction of the initial austenite still remains untransformed: $3.08(16) \%$ in the $\mathrm{Al}_{0.4}$ sample and 4.66(20)\% in the $\mathrm{Al}_{1.8}$ sample. Further increase in deformation does not lead to significant variations in the austenite fraction up to the fracture of the specimen. This indicates that no increase in stress occurs in the sample volume probed by the X-ray beam beyond the maximum in the stress-strain curve. The same trend in the austenite fraction during the deformation process has been obtained when using either the Fullprof or the MAUD software packages for the Rietveld analysis of the diffraction data, the difference in the obtained values for the retained austenite fraction lies within a relative error of $12 \%$ (the absolute difference ranges from 0.4 to $0.9 \%$ depending on the fraction). The average lattice parameter undergoes a continuous increase during the deformation process in both samples, with the larger changes occurring in the first deformation steps.

The specific process route to prepare TRIP steels (see Section 2.1 ) leads to the presence of two types of austenite grains with different size and morphology: "film-type" grains located inside the bainitic colonies and "blocky-type" grains surrounded by ferritic and bainitic grains $[19,20]$. The former subset of austenite grains are known to remain untransformed until the onset of necking, so that only the blocky-type austenite grains are responsible for the observed decrease in austenite fraction [16,53]. Our previous HEXRD experiments on TRIP steels [42] revealed a distribution in carbon content and grain size within the blocky-type austenite grains, and a gradual change in both parameters during the martensitic transformation when cooling the material below room temperature. The observed evolution of the austenite fraction with deformation with a plateau between $2 \%$ and $4 \%$ deformation points to an additional parameter affecting the stability of the austenite grains. Moreover when the fracture of the specimen takes place, only the film-type grains together with a small fraction of the blocky-type grains with a high carbon content and a relatively small grain size are expected to be present in the microstructure.

\subsubsection{Load partitioning}

The occurrence of elastic phase strains $\left(\left\langle\varepsilon_{p h}\right\rangle\right)$ with the applied stress, as determined from the shift in the diffraction peaks using Eq. (1), is shown in Fig. 7 for both the austenite phase and the ferritic matrix in the two studied TRIP samples. The elastic response reveals 

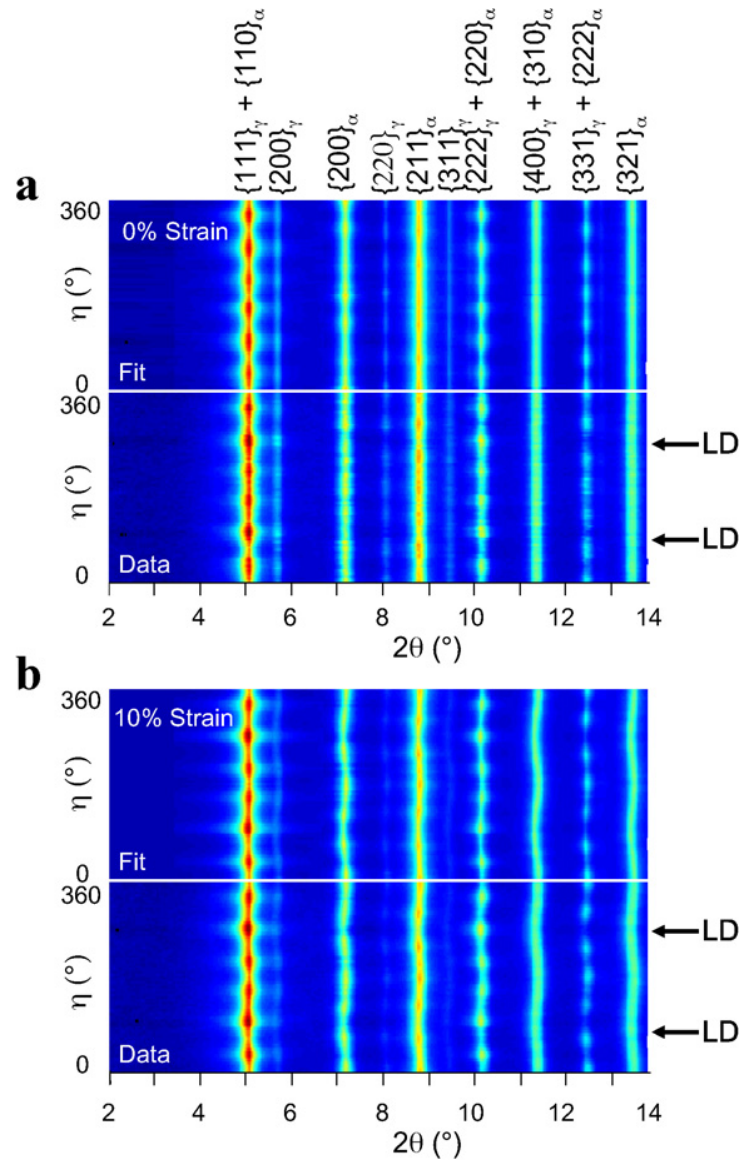

Fig. 5. Map plot of the experimental (bottom) and calculated (top) diffraction pattern as a function of the azimuth angle $(\eta)$ for the $\mathrm{Al}_{0.4}$ sample at $\omega=90^{\circ}$ for: (a) $0 \%$ and (b) $10 \%$ strain. The corresponding one-dimensional patterns have been obtained by performing successive integrations along the scattering angle over regions of the detector covering an angle of $5^{\circ}$ along $\eta$. The presence of texture in both phases is evidenced by significant intensity variations with $\eta$. The loading direction (LD) is indicated in the figure. Variations in peak positions with $\eta$, due to the presence of elastic strain, are observed in both phases for $10 \%$ strain. The Miller indices for the ferrite $(\alpha)$ and austenite $(\gamma)$ reflections are also shown in the figure.

an approximately linear behaviour for applied stresses lower than the macroscopic yield point. It is noteworthy that the strains in the austenite phase are larger than in the ferritic matrix. This difference is present from the beginning of the deformation, and is larger for the $\mathrm{Al}_{1.8}$ than for the $\mathrm{Al}_{0.4}$ sample. However, a similar elastic behaviour would be expected for both the $\alpha$-matrix and the retained austenite in the TRIP microstructure, based on the reported bulk Young's modulus of $E^{\alpha}=218 \mathrm{GPa}$ and $E^{\gamma}=217 \mathrm{GPa}$ [54]. These values slightly deviate from the ones obtained for singlephase steels of $E^{\alpha}=210 \mathrm{GPa}$ and $E^{\gamma}=195 \mathrm{GPa}$ [51]. The relatively large difference in the elastic behaviour between the austenite phase and the ferritic matrix, as compared to the reported difference in Young's modulus between both crystallographic phases in a TRIP microstructure, may be ascribed to: (1) the martensitic transformation of the relatively unstable low-carbon austenite grains with a larger grain volume in the elastic region induced by the applied stress. The low-carbon austenite grains are less stable and transform first leading to a higher average carbon content of the remaining austenite phase. This results in an increase in the average lattice parameter of the remaining austenite phase [40-42]. Our recent in situ synchrotron studies on these TRIP steel grades during cooling from room temperature down to $100 \mathrm{~K}$ [39] revealed a carbon enrichment of $\Delta x_{c}=0.047 \mathrm{wt} . \%\left(\mathrm{Al}_{0.4}\right)$ and $0.136 \mathrm{wt} . \%$ $\left(\mathrm{Al}_{1.8}\right)$ when the lowest temperature is reached. These values were
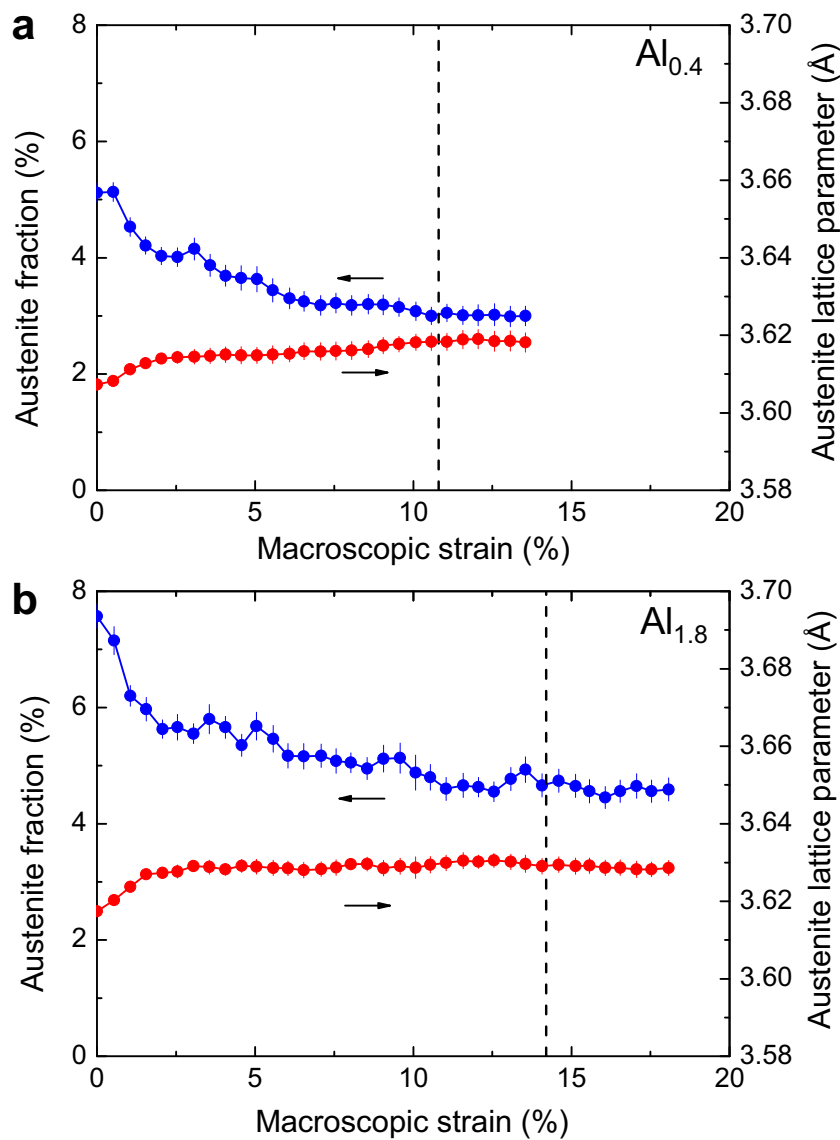

Fig. 6. Evolution of the austenite fraction and average lattice parameter with the macroscopic strain for the (a) $\mathrm{Al}_{0.4}$ and (b) $\mathrm{Al}_{18 .}$ samples, respectively. The vertical dashed line indicates the maximum in the engineering stress-strain curve. The arrows in the figure indicate the vertical scale for the displayed curves: austenite fraction (left axis) for the blue dots, and austenite lattice parameter (right axis) for the red dots. (For interpretation of the references to color in this figure legend, the reader is referred to the web version of the article.)

obtained from the variation in the austenite lattice parameter with temperature, after correcting for the expected thermal contraction of the lattice. The austenite phase is therefore expected to experience a higher carbon enrichment in the $\mathrm{Al}_{1.8}$ steel due to

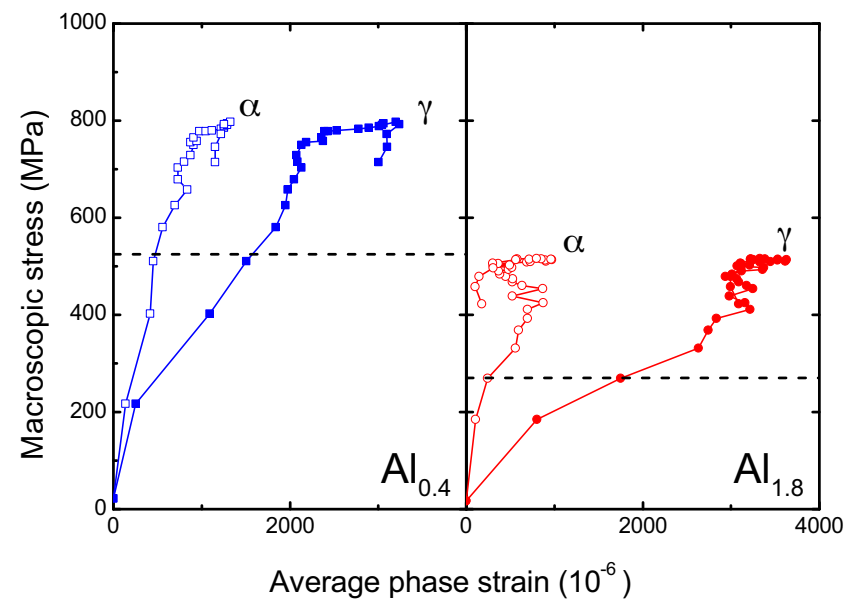

Fig. 7. Evolution of the average phase strain with the macroscopic stress in both the ferrite $(\alpha)$ and austenite $(\gamma)$ phases for the two studied TRIP steels. The horizontal dashed line indicates the yield strength $\left(R_{p 0.2}\right)$ in each case. 
Table 4

Phase stress as a function of the engineering strain $(\varepsilon)$ in the case of ferrite $(\alpha)$ and austenite $(\gamma)$ for the two studied TRIP steels. $\sigma_{33}$ corresponds to the largest principal stress (see text).

\begin{tabular}{|c|c|c|c|c|c|}
\hline \multicolumn{3}{|l|}{$\mathrm{Al}_{0.4}$} & \multicolumn{3}{|l|}{$\mathrm{Al}_{1.8}$} \\
\hline$\varepsilon(\%)$ & $\sigma_{33}^{\alpha}(\mathrm{MPa})$ & $\sigma_{33}^{\gamma}(\mathrm{MPa})$ & $\varepsilon(\%)$ & $\sigma_{33}^{\alpha}(\mathrm{MPa})$ & $\sigma_{33}^{\gamma}(\mathrm{MPa})$ \\
\hline 0 & - & - & 0 & - & - \\
\hline 0.5 & 193.1(6) & 191(3) & 0.5 & $167(1)$ & $214(7)$ \\
\hline 2.0 & $418.5(5)$ & $581(8)$ & 2.1 & $328(1)$ & $637(12)$ \\
\hline 10.8 & $557(1)$ & $746(23)$ & 14.1 & $414(1)$ & $914(15)$ \\
\hline
\end{tabular}

the preferred transformation of the low-carbon austenite grains, and consequently a larger change in the average lattice parameter of the remaining austenite with respect to the starting condition. (2) The contribution of the newly formed martensite phase to the elastic properties of the ferritic matrix. (3) A non-random distribution of the diffracting grains within each phase. The Young's modulus varies significantly for different crystallographic directions, especially in the austenite [51], and the resultant modulus in the polycrystalline material would be dominated by those crystal orientations with a larger population of grains.

Significant differences in the resultant phase stiffness would lead to load partitioning between the ferritic matrix and the retained austenite already in the elastic zone, where the mechanically harder phase would bear a higher load. Table 4 collects the experimental values of the phase stress for selected engineering strain levels for the constituent crystallographic phases in the microstructure, as derived from the ellipsoidal form of the diffraction rings. Clear differences in the phase stress between austenite and the ferritic matrix are observed in the first stages of deformation, especially in the $\mathrm{Al}_{1.8}$ sample. These differences point to the occurrence of load partitioning between the austenite and the ferritic matrix already in the elastic zone. The mechanically harder austenite phase seems to bear a higher load and would therefore act as a reinforcement of the softer ferritic matrix. This effect is less pronounced in the $\mathrm{Al}_{0.4}$ sample. Our previous results indicated the presence of a small amount of martensite in the room-temperature microstructure of the $\mathrm{Al}_{0.4}$ sample at zero stress [41]. This martensite phase would act as an additional reinforcement of the ferritic matrix, so that its difference in stiffness with respect to the austenite phase becomes smaller.

When the macroscopic yield point is surpassed, the dependence of the average phase strain with the applied stress deviates from linearity. This effect is especially noticeably in the change of slope in the average austenite strain, and indicates the beginning of the plastic deformation of the austenite grains. At this point, it is expected that a number of the ferritic grains have already undergone plastic deformation due to the lower yield point of ferrite as compared to austenite [38]. When the austenite starts to yield, the ferritic matrix already contains a fraction of the newly formed harder martensite, and part of the load is transferred back progressively to the ferritic matrix. In this elasto-plastic regime, both interphase and intergranular microstresses are expected to develop in the constituent phases of the evolving microstructure [51]. The macroscopic yield point seems to have a correlation with the start of the yielding phenomena in the austenite grains. Moreover, it is at the stage when the austenite has already started to yield that the second step in the martensitic transformation of the retained austenite is initiated (see Fig. 6). Close to the tensile strength, the great majority of the grains in the microstructure display a large degree of plastic deformation.

\subsubsection{Texture evolution}

In addition to the mechanically induced martensitic transformation of the metastable austenite grains and the occurrence of phase stresses, the constituent grains of the TRIP microstructure may react to the applied stress by undergoing rotations in orientation space. The resultant texture evolution would have a non-negligible effect on the elastic and plastic anisotropy of the polycrystalline aggregate, and also on the critical stress to trigger the martensitic transformation. The changes in texture during deformation at room temperature are displayed in Figs. 8 and 9 for the $\mathrm{Al}_{0.4}$ and $\mathrm{Al}_{1.8}$ samples, respectively, in terms of inverse pole figures for selected engineering strain levels. The starting texture state for both samples corresponds to a non-random distribution of the grains in both the ferritic matrix and the retained austenite. This is due to a memory effect of the texture that was formed during the prior hot-rolling process and the subsequent heat treatment to obtain the room-temperature TRIP microstructure. The rolling texture components are generally designated as $\{h k l\}\langle u v w\rangle$, where $\{h k l\}$ are the Miller indices of the crystal planes parallel to the rolling direction, while $\langle u v w\rangle$ corresponds to the zone axis symbols of the crystallographic direction along the rolling direction. The ferritic matrix presents a preferred $\{111\}\langle 110\rangle$ texture component, which is more pronounced in the $\mathrm{Al}_{0.4}$ sample. This texture component is reported to become strong in bcc metals for increasing deformation levels during the rolling stage [55]. The texture state in the austenite phase presents two main components: the deformation-type $\{110\}\langle 100\rangle$ and the recrystallization-type $\{110\}\langle 111\rangle$ (see Ref. [56]). Both components are present in the studied samples, but the former is more intense in the $\mathrm{Al}_{0.4}$ sample, while the $\left\{\begin{array}{ll}1 & 10\end{array}\right\}\langle 111\rangle$ appears to be stronger in the $\mathrm{Al}_{1.8}$ sample. During the heat treatment after the rolling process to produce the TRIP microstructure, a transfer of texture takes place between the parent and product phases during the relevant phase transformations. In fact, a main product component during a $\mathrm{fcc} \rightarrow$ bcc transformation of the two reported fcc texture components in these materials is the bcc $\{111\}\langle 110\rangle$ component, according to the Kurdjumov-Sachs relationship [56].

This non-random texture plays a relevant role in the deformation and transformation behaviour of these TRIP steels under increasing tensile stress levels at room temperature. During the first deformation steps (up to $2 \%$ strain), strong changes in the texture of the ferritic matrix are not observed. However, the $\langle 100\rangle$ component vanishes in the austenite phase in the first stages of deformation, while its $\langle 111\rangle$ component still remains and even gets somewhat stronger in the $\mathrm{Al}_{0.4}$ sample. The disappearance of the $\langle 100\rangle$ austenite component seems to take place simultaneously with the first step in the martensitic transformation observed in the evolution of the austenite phase fraction during deformation (Fig. 6). Since our previous studies did not reveal a bimodal distribution of the local carbon content and the grain volume [40-42], the two-step transformation behaviour observed in the metastable austenite can only be attributed to the two texture components that are present in this phase at the start of the deformation process. Austenite grains oriented with the $\langle 100\rangle$ crystallographic direction along the loading direction are indeed reported to transform preferentially [57]. Therefore, the grains with this orientation with respect to the applied stress, together with a relatively low carbon content and a large grain volume [40-42], will transform at the beginning of the tensile test. The depletion of these $\langle 100\rangle$-oriented grains seems to cause a delay in the martensitic transformation of the austenite. Once the critical stress of the transformation of the less favourably oriented grains has been overcome, the transformation resumes and continues up to the tensile strength of the material. At this point, only the small austenite grains with a high carbon content will remain untransformed [53]. The martensitic transformation also enhances the $\langle 110\rangle$ component of the ferritic matrix, according to the Kurdjumov-Sachs relationship [56]. In the plastic regime, the grains in both crystallographic phases are also undergoing significant rotations, so that the bcc $\langle 110\rangle$ 


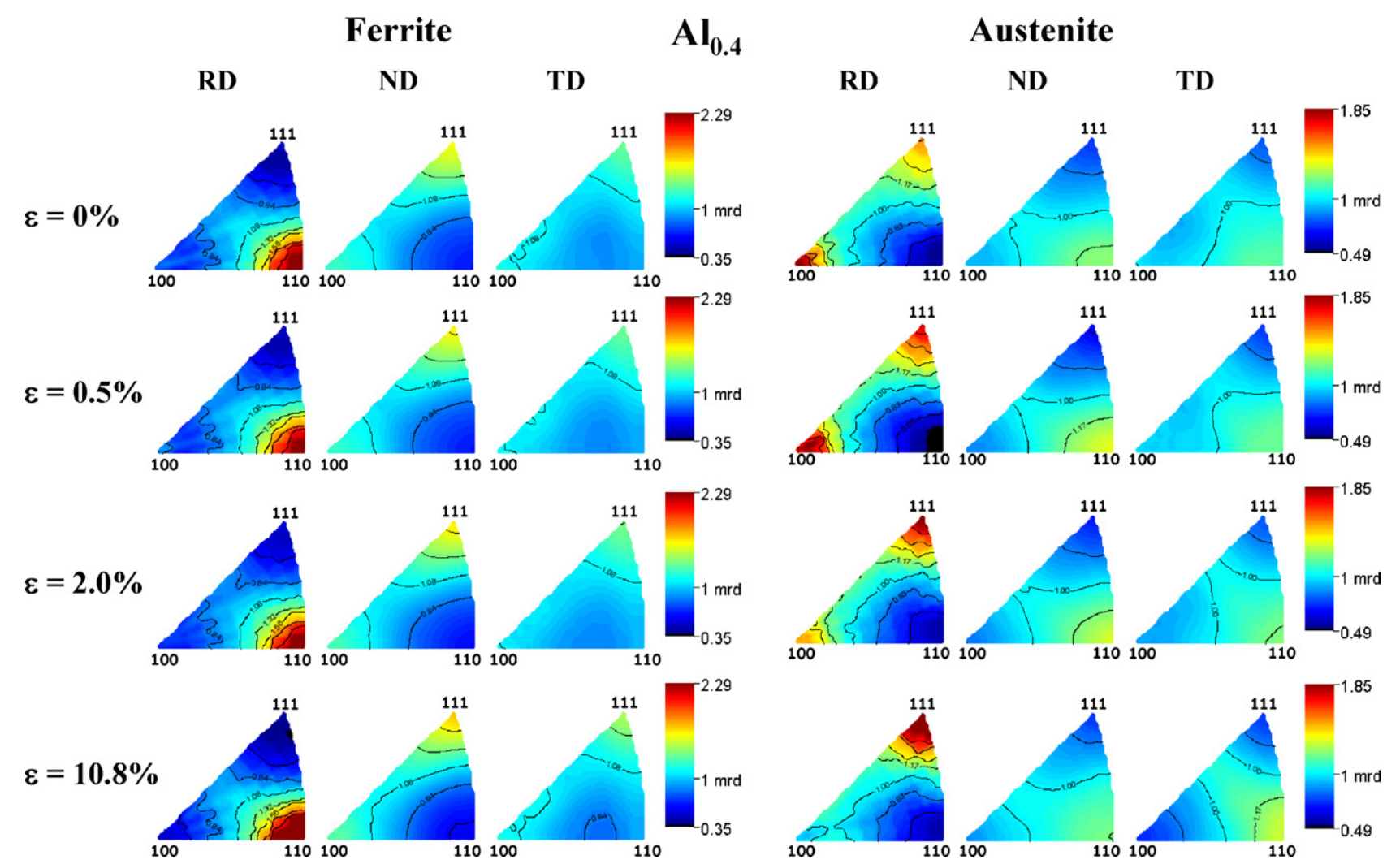

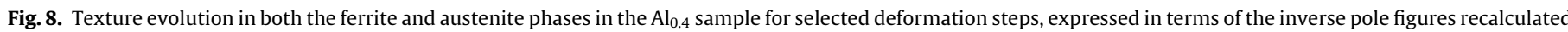
from the ODFs obtained from the analysis of the diffraction data. The scale is in multiples of random distribution (mrd).

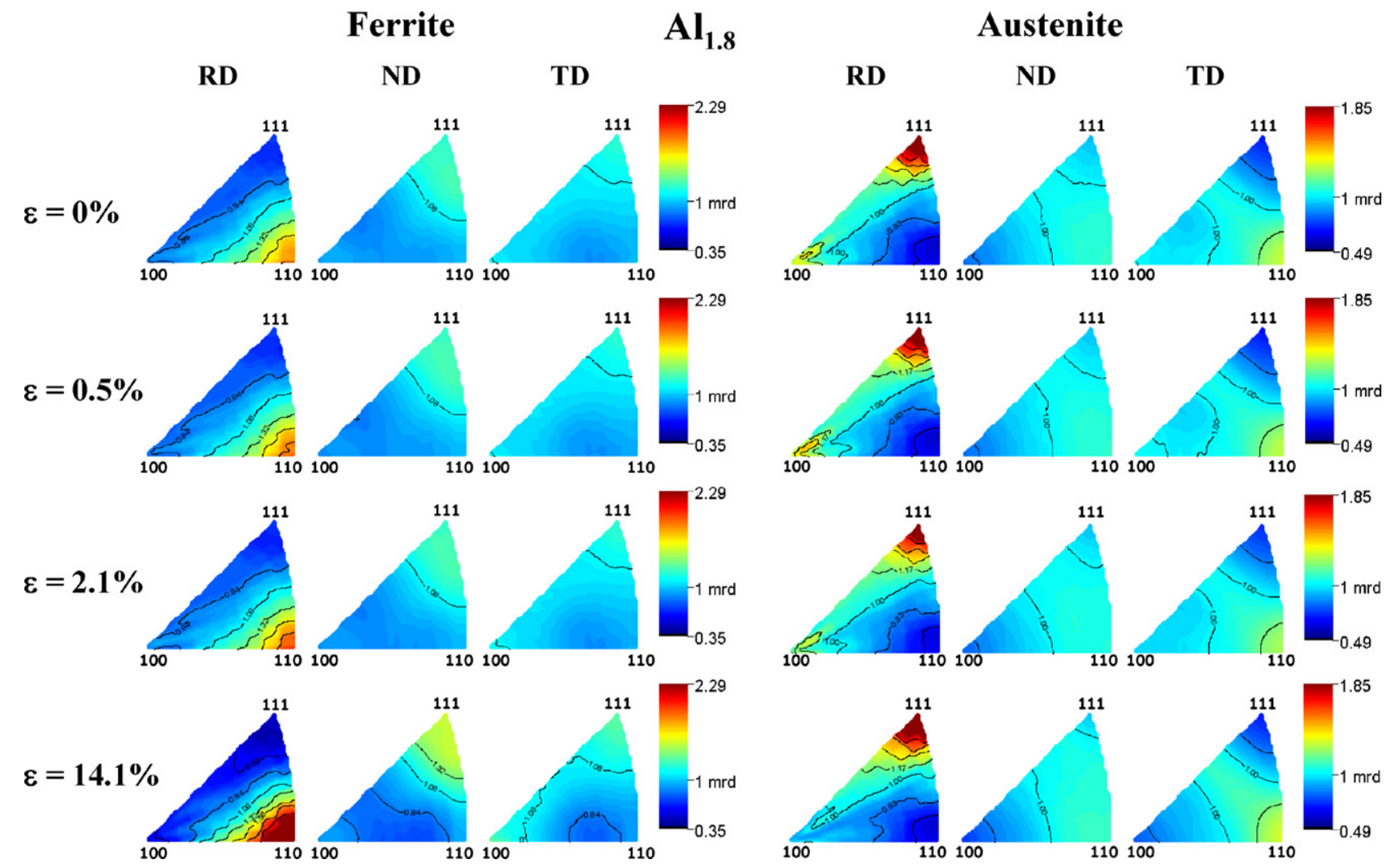

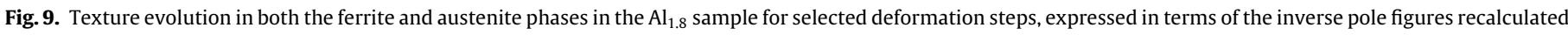
from the ODFs obtained from the analysis of the diffraction data. The scale is in multiples of random distribution (mrd). 

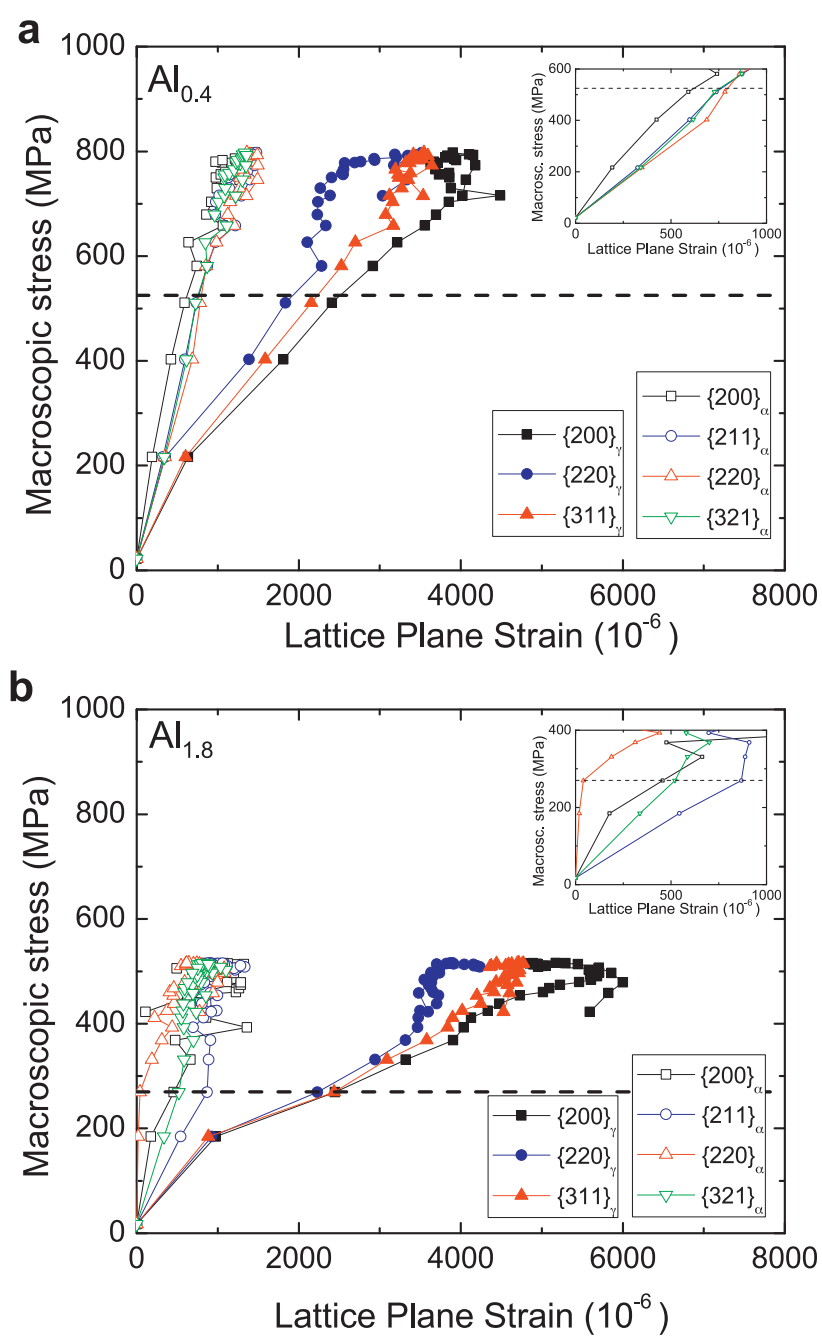

Fig. 10. Evolution of the average lattice plane strains with the macroscopic stress corresponding to selected (weakly overlapping or non-overlapping) ferrite $(\alpha)$ and austenite $(\gamma)$ reflections for the (a) $\mathrm{Al}_{0.4}$ and (b) $\mathrm{Al}_{1.8}$ samples, respectively. The inset shows the low-stress response of the ferritic lattice planes in detail. The horizontal dashed line indicates the yield strength $\left(R_{p 0.2}\right)$ in each case.

and the fcc $\langle 111\rangle$ deformation components gradually become dominant.

\subsection{Average lattice plane response}

Since the response of each phase to the applied stress depends on the intrinsic crystal anisotropy and the grain orientation distribution, it is important to evaluate the response of different families of planes within each constituent phase and relate it to the observed texture evolution. Fig. 10 shows the average elastic strain for selected crystallographic planes of both the ferritic matrix and the retained austenite in both TRIP steels. The lattice response follows an approximately linear behaviour up to the macroscopic yield point, while strong $h k l$-dependent deviations from linearity are clearly visible in the plastic regime. The elastic response of the austenitic families of planes complies with the cubic elastic anisotropy, manifested in the reported trend in the $h k l$-dependent Young's modulus: $E_{200}^{\gamma}<E_{311}^{\gamma}<E_{220}^{\gamma}$ [51]. However, larger differences in the lattice plane strains are observed in the $\mathrm{Al}_{0.4}$, as compared with the relatively close behaviour observed in the $\mathrm{Al}_{1.8}$. This effect can be ascribed to the stronger texture evolution in the $\mathrm{Al}_{0.4}$ sample during the first stages of the deformation process, which leads to a more pronounced load partitioning between different families of grains within the austenite phase. The trend in the ferritic $h k l$-dependent Young's modulus $\left(E_{200}^{\alpha} \approx E_{321}^{\alpha} \approx E_{211}^{\alpha} \approx\right.$ $E_{110}^{\alpha}$ [51]) seems not to be fulfilled. This is especially the case in the $\mathrm{Al}_{1.8}$ sample, probably due to the texture evolution and the additional contribution of the newly formed martensite to the stiffness of the ferritic matrix.

The onset of non-linearity reveals the occurrence of crystallographic slip at the local scale, which is characteristic for the beginning of the plastic regime. This yielding phenomenon does not take place simultaneously in all the grains, but seems to depend markedly on the $h k l$-reflection. Furthermore, the austenitic families of planes behave approximately linearly up to the macroscopic yield point, while some $h k l$-planes in the ferritic matrix seem to have started to yield at lower stress levels. This fact enforces the idea that the macroscopic yield point in the studied TRIP steels seems to be governed by the start of the yielding phenomenon in the austenitic grains. In the plastic regime, the observed $h k l$-dependent response of the ferritic matrix and the retained austenite, together with the significant changes in texture, point to a complex load redistribution within the different grains of each phase and also between both crystallographic phases.

\section{Conclusions}

We have performed in situ high-energy synchrotron X-ray diffraction experiments in two aluminium-containing TRIP steels under tensile stress at room temperature, in order to unravel the complex deformation and transformation mechanisms that take place in these materials at the microscale during the different stages of the tensile test. The main results of this study are:

1. The combination of in situ X-ray diffraction in transmission geometry and uniaxial loading allows to detect relatively small fractions of metastable austenite $(<10 \%)$ in the bulk multiphase TRIP microstructure, and to reliably monitor small changes in the austenite fraction during deformation. Understanding the austenite behaviour in the bulk is crucial to tailor the mechanical response of metastable TRIP steels. This understanding cannot be obtained by regular tensile tests and standard X-ray diffraction in reflection geometry where the probed sample volume lies only a few microns below the surface. In this case, prior thermo-mechanical processing of the material may affect the austenite stability close to the sample surface. We have found that an increased aluminium content leads to a higher volume fraction of retained austenite at room temperature and to a larger uniform elongation during the tensile test. For an aluminium content of $0.4 \mathrm{wt} . \%$, a partial transformation of the metastable austenite into martensite already takes place during the quenching step from $673 \mathrm{~K}$ to room temperature (for a bainitic holding time of $60 \mathrm{~s}$ ). The presence of a small amount of martensite and a lower fraction of metastable austenite at room temperature have an important effect on the mechanical behaviour of TRIP steel in terms of increasing the yield point and tensile strength, but also deteriorating the formability of the material. The use of a two-dimensional detector during the diffraction experiment and the implementation of a combined data treatment of all the recorded data sets has allowed us to link the observed austenite transformation behaviour to the texture evolution and the load partitioning between the constituent phases of the microstructure.

2. In the two studied TRIP samples, the martensitic transformation of the metastable austenite occurs in a two-step process. Since our previous studies on these TRIP steel grades revealed a continuous distribution in carbon content and grain size in the austenite phase, the observed transformation behaviour has 
been ascribed to the presence of two main texture components in the austenite phase in the starting TRIP microstructure. The $\langle 100\rangle$ component along the loading direction seems to be responsible for the first step in the transformation behaviour, and becomes depleted after about $2 \%$ engineering strain. This change in texture in the austenite phase appears to be more pronounced in the $\mathrm{Al}_{0.4}$ sample. The remaining austenite continues to transform gradually up to the maximum in the engineering stress-strain curve in both steels. This opens the possibility of tailoring the austenite stability for improved combinations of strength/formability by modifying three main microstructural parameters: the local carbon content, the grain size and the texture.

3. The evolution of the elastic strains in the ferritic matrix and in the retained austenite revealed the occurrence of load partitioning before reaching the macroscopic yield strength. The redistribution of stresses becomes even more complex in the plastic regime due to the progressive yielding of the different grains in the polycrystalline material. The macroscopic yielding seems to be governed by the plastic deformation of the austenite grains. These results clearly demand the development of micromechanical models that are capable of simulating not only the average response of the phases, but also the behaviour of different families of grains within each phase, taking into account the texture evolution, the gradual formation of martensite and the complex distribution of stresses at different stages in the tensile test. This would require taking into account the different bcc phases and their evolution during deformation, instead of using the current approach of considering the austenite grains embedded in a generic ferritic matrix.

\section{Acknowledgements}

We acknowledge the European Synchrotron Radiation Facility for provision of synchrotron radiation facilities, and we would like to thank L. Margulies for assistance in using the ID11 beam line. This research is supported by the Dutch Technology Foundation STW, applied science division of NWO and the Technology Program of the Ministry of Economic Affairs.

\section{References}

[1] J.W. McAuley, Environ. Sci. Technol. 37 (2003) 5414

[2] H.E. Friedrich, Adv. Eng. Mater. 5 (2003) 105.

[3] H.E. Friedrich, P. Steinle, G. Kopp, R. Schöll, Mater. Sci. Forum 638-642 (2010) 3.

[4] R. Kuziak, R. Kawala, S. Waengler, Arch. Civ. Mech. Eng. 8 (2008) 103.

[5] B.C. De Cooman, Curr. Opin. Solid State Mater. Sci. 8 (2004) 285.

[6] S. Thibaud, N. Boudeau, J.C. Gelin, J. Mater. Proc. Technol. 177 (2006) 433.

[7] H.N. Han, C.S. Oh, G. Kim, O. Kwon, Mater. Sci. Eng. A 499 (2009) 462.

[8] M.R. Berrahmoune, S. Berveiller, K. Inal, A. Moulin, E. Patoor, Mater. Sci. Eng. A 378 (2004) 304

[9] H. Lee, H.J. Koh, C.H. Seo, N.J. Kim, Scripta Mater. 59 (2008) 83.

[10] G. Lacroix, T. Pardoen, P.J. Jacques, Acta Mater. 56 (2008) 3900.

[11] P.J. Jacques, Curr. Opin. Solid State Mater. Sci. 8 (2004) 259.

[12] W. Shi, L. Li, C.X. Yang, R.Y. Fu, L. Wang, P. Wollants, Mater. Sci. Eng. A 429 (2006) 247.

[13] D.W. Suh, S.J. Park, T.H. Lee, C.S. Oh, S.J. Kim, Metall. Mater. Trans. A 41A (2010) 397.

[14] A.M. Streicher-Clarke, J.G. Speer, D.K. Matlock, B.C. DeCooman, D.L. Williamson, Metall. Mater. Trans. A 36A (2005) 907.
[15] M. Mukherjee, O.N. Mohanty, S. Hashimoto, T. Hojo, K. Sugimoto, ISIJ Int. 46 (2006) 316.

[16] P.J. Jacques, J. Ladrière, F. Delannay, Metall. Mater. Trans. A 32A (2001) 2759.

[17] B.X. Huang, X.D. Wang, Y.H. Rong, Scripta Mater. 57 (2007) 501.

[18] X.D. Wang, B.X. Huang, L. Wang, Y.H. Rong, Metall. Mater. Trans. A 39A (2008) 1.

[19] I.B. Timokhina, P.D. Hodgson, E.V. Pereloma, Metall. Mater. Trans. A 35A (2004) 2331.

[20] S. Zaefferer, J. Ohlert, W. Bleck, Acta Mater. 52 (2004) 2765.

[21] R. Petrov, L. Kestens, A. Wasilkowska, Y. Houbaert, Mater. Sci. Eng. A 447 (2007) 285.

[22] J. Bouquerel, K. Verbeken, B.C. De Cooman, Acta Mater. 54 (2006) 1443.

[23] F. Lani, Q. Furnémont, T. Van Rompaey, F. Delannay, P.J. Jacques, T. Pardoen, Acta Mater. 55 (2007) 3695.

[24] D.D. Tjahjanto, S. Turteltaub, A.S.J. Suiker, S. van der Zwaag, Phil. Mag. 88 (2008) 3369.

[25] V. Uthaisangsuk, U. Prahl, W. Bleck, Int. J. Fract. 157 (2009) 55.

[26] D.D. Tjahjanto, S. Turteltaub, A.S.J. Suiker, S. van der Zwaag, Adv. Eng. Mater. 11 (2009) 153.

[27] K.-D. Liss, A. Bartels, A. Schreyer, H. Clemens, Texture Microstruct. 35 (2003) 219.

[28] S.R. Bhatia, P.G. Khalifah, D.J. Pochan, P.G. Radaelli, MRS Symposium Proceedings, vol. 840, Materials Research Society, Warrendale, Pennsylvania, 2005.

[29] N. Jia, R. Lin Peng, Y.D. Wang, S. Johansson, P.K. Liaw, Acta Mater. 56 (2008) 782.

[30] K. Yan, K.-D. Liss, U. Garbe, J. Daniels, O. Kirstein, H. Li, et al., Adv. Eng. Mater 11 (2009) 771

[31] C.C. Aydiner, J.V. Bernier, B. Clausen, U. Lienert, C.N. Tomé, D.W. Brown, Phys Rev. B 80 (2009) 024113.

[32] M.L. Young, M.F.X. Wagner, J. Frenzel, W.W. Schmahl, G. Eggeler, Acta Mater. 58 (2010) 2344.

[33] M.R. Daymond, M. Preuss, B. Clausen, Acta Mater. 55 (2007) 3089.

[34] P.J. Jacques, Q. Furnemont, S. Godet, T. Pardoen, K.T. Conlon, F. Delannay, Phil Mag. 86 (2006) 2371.

[35] K.S. Choi, W.N. Liu, X. Sun, M.A. Khaleel, Y. Ren, Y.D. Wang, Metall. Mater. Trans A 39A (2008) 3089.

[36] S. Cheng, X.L. Wang, Z. Feng, B. Clausen, H. Choo, P.K. Liaw, Metall. Mater. Trans A 39A (2008) 3105.

[37] O. Muránsky, P. Šittner, J. Zrník, E.C. Oliver, Acta Mater. 56 (2008) 3367.

[38] N. Jia, Z.H. Cong, X. Sun, S. Cheng, Z.H. Nie, Y. Ren, et al., Acta Mater. 57 (2009) 3965.

[39] N.H. van Dijk, A.M. Butt, L. Zhao, J. Sietsma, S.E. Offerman, J.P. Wright, S. van der Zwaag, Acta Mater. 53 (2005) 5439.

[40] E. Jimenez-Melero, N.H. van Dijk, L. Zhao, J. Sietsma, S.E. Offerman, J.P. Wright, S. van der Zwaag, Scripta Mater. 56 (2007) 421.

[41] E. Jimenez-Melero, N.H. van Dijk, L. Zhao, J. Sietsma, S.E. Offerman, J.P. Wright, S. van der Zwaag, Acta Mater. 55 (2007) 6713.

[42] E. Jimenez-Melero, N.H. van Dijk, L. Zhao, J. Sietsma, S.E. Offerman, J.P. Wright S. van der Zwaag, Acta Mater. 57 (2009) 533.

[43] H.F. Poulsen, Three-Dimensional X-Ray Diffraction Microscopy Mapping Polycrystals and their Dynamics. Springer Tracts in Modern Physics 205, Springer, Berlin, 2004.

[44] J.-C. Labiche, O. Mathon, S. Pascarelli, M.A. Newton, G.G. Ferre, C. Curfs, et al., Rev. Sci. Instrum. 78 (2007) 091301.

[45] A.P. Hammersley, S.O. Svensson, M. Hanfland, A.N. Fitch, D. Hausermann, High Pressure Res. 14 (1996) 235

[46] J. Rodríguez-Carvajal, Physica B 192 (1993) 55.

[47] L. Lutterotti, S. Matthies, H.R. Wenk, CPD Newslett. 21 (1999) 14.

[48] I. Lonardelli, H.-R. Wenk, L. Lutterotti, M. Goodwin, J. Synchrotron Radiat. 12 (2005) 354.

[49] L. Lutterotti, M. Bortolotti, G. Ischia, I. Lonardelli, H.R. Wenk, Z. Kristallogr. Suppl 26 (2007) 125.

[50] S. Matthies, H.G. Priesmeyer, M.R. Daymond, J. Appl. Crystallogr. 34 (2001) 585.

[51] M.T. Hutchings, P.J. Withers, T.M. Holden, T. Lorentzen, Introduction to the Characterization of Residual Stress by Neutron Diffraction, Taylor \& Francis, New York, 2005.

[52] C.P. Scott, J. Drillet, Scripta Mater. 56 (2007) 489

[53] D.Q. Bai, A. Di Chiro, S. Yue, Mater. Sci. Forum 284-6 (1998) 253.

[54] O. Muránsky, P. Šittner, J. Zrník, E.C. Oliver, Metall. Mater. Trans. A 39A (2008) 3097.

[55] D. Raabe, K. Lücke, Mater. Sci. Forum 157-162 (1994) 597.

[56] M.P. Butrón-Guillén, J.J. Jonas, R.K. Ray, Acta Metall. Mater. 42 (1994) 3615.

[57] E.C. Oliver, P.J. Withers, M.R. Daymond, S. Ueta, T. Mori, Appl. Phys. A 74 (2002) S1143. 